\title{
Augmentative and Alternative Communication (AAC) for a patient with a nonfluent/ agrammatic variant of PPA in the mutism stage
}

\author{
Jolanta Góral-Półrola', Paweł Półrola², Natalia Mirska ${ }^{3}$ Andrzej Mirski³ \\ Izabela Herman-Sucharska5, Maria Pąchalska ${ }^{3,4}$ \\ ${ }^{1}$ Old Polish University, Kielce, Poland \\ 2 Department of Health Sciences, Jan Kochanowski University, Kielce, Poland \\ ${ }^{3}$ Department of Neuropsychology, Andrzej Frycz-Modrzewski University, Krakow, Poland \\ ${ }^{4}$ Center for Cognition and Communication, New York, USA \\ ${ }^{5}$ Department of Electroradiology, Faculty of Health Sciences, Jagiellonian University, Kraków, Poland
}

Góral-Półrola J, Półrola P, Mirska N, Mirski A, Herman-Sucharska I, Pąchalska M. Augmentative and Alternative Communication (AAC) for a patient with a nonfluent/ agrammatic variant of PPA in the mutism stage. Ann Agric Environ Med. 2016; 23(1): 182-192. doi: $10.5604 / 12321966.1196877$

\begin{abstract}
Ibstract
Introduction. The paper presents an example of the successful administration of the Augmentative and Alternative Communication (AAC) system. Such an approach is of particular significance in cases of patients with speech and language deterioration, which is observed in a nonfluent/agrammatic variant of primary progressive aphasia (PPA-G).

Regaining the ability to communicate with others proves to be very important for the patients' self-esteem and enables them to restore previously broken social bonds.

Case history. The patient A.G., aged 73, a right-handed woman, had been a teacher of Polish before suffering from speech disorders of the PPA-G type. As the disease progressed, her communication deteriorated and finally she developed mutism. The patient was given a clinical and imaging-supported diagnosis of an isolated nonfluent/ agrammatic variant of primary progressive aphasia (PPA-G). The Augmentative and Alternative Communication (AAC) system specially designed for her needs was introduced to help the patient to regain the possibility to communicate. After 20 sessions of training with the use of simple equipment she was again able to communicate non-verbally with her son and with the staff of the nursing home. At the same time, a considerable improvements in her social functioning, including daily activities, was observed. Conclusions. Loss of the ability to communicate with others has a serious impact upon a patient's quality of life, and often results in withdrawal and an inability to lead an independent life. The introduction of the Augmentative and Alternative Communication (AAC) system proves to be a great help, not only for regaining the ability to communicate, but also for the restoration of social bonds. In consequence, the previously mute patient begins to show signs of social cooperation.
\end{abstract}

\section{Key words}

frontotemporal dementia, primary progressive aphasia, AAC

\section{INTRODUCTION}

One of the main goals of modern medicine is to improve the quality of life of persons with a neurological illness, especially one which leads to language disturbances. In the case of patients with PPA, in whom, as the disease progresses and communication is lost, this aim might be achieved by the use of Augmentative and Alternative Communication (AAC) strategies. AAC includes all forms of communication (other than oral speech) used to express thoughts, needs, wants, and ideas. We all use AAC when we make facial expressions or gestures, use symbols or pictures, or write. People with severe speech or language problems rely on AAC to supplement existing speech or replace speech that is not functional. Special augmentative aids, such as picture and symbol communication boards and electronic devices, are available to help people express themselves. These may increase social interaction, school performance, and feelings of self-esteem.

Address for correspondence: Maria Pąchalska,Chair of Neuropsychology, Andrzej Frycz Modrzewski Krakow, University, Herlinga-Grudzinskiego 1, 30-705 Kraków, Poland

E-mail: neuropsycholgia23@o2.pl

Received: 24 August 2015; accepted: 13 October 2015
Traditionally, AAC strategies have been designed for individuals for whom oral speech is not a viable option. Common clinical practice has expanded AAC use to being a tool for cognitive retraining or remediation. Although technological developments offer the potential for vastly improved communication and inclusion for some individuals with severe communication disorders, technology alone does not result in successful communication [1].

Primary progressive aphasia (PPA) is an important recentlyemphasized clinical syndrome that is a common early manifestation of Pick's disease and Pick complex pathology. It is defined clinically as slowly progressive language disturbance that remains relatively isolated from other cognitive or behavioural deficits for at least 2 years [2]. In other words, it is a language disorder that involves changes in the ability to speak, read, write, and understand what others are saying. It is associated with a disease process that causes atrophy in the frontal and temporal areas of the brain, and is distinct from aphasia resulting from a stroke [3]. Asymmetric atrophy involves the perisylvian regions of the left hemisphere.

The clinical syndrome is characterized by a slow, insidious decline in the specific aspects of language functioning, with onset typically in the fifth or sixth decade of life. The earliest 
symptoms are often so subtle that only the patient or family members can detect them. Unlike aphasia due to a stroke, the onset is not accompanied by an acute neurological event. Despite the gradual worsening of language functions, the non-linguistic aspects of cognition may remain relatively intact for several years.

PPA generally does not produce changes in behaviour or personality until the later stages of the disease. Most people with progressive aphasia maintain the ability to care for themselves, maintain outside interests, and, in some instances, remain employed for a few years after the onset of the disorder.

Subsequently, PPA may become associated with behavioural changes similar to those in frontal lobe dementia (FLD), extrapyramidal manifestations, and apraxia similar to corticobasal degeneration (CBD) and with motor neuron disease. Both the common non-fluent or logopenic variety leading to mutism (frontal involvement) and fluent or semantic varieties (temporal involvement) are recognized ${ }^{1}$.

Both a non-fluent variety leading to mutism and a fluent subtype with predominantly semantic impairment are now recognized. Although early cases of focal deterioration of language functions were described by the pioneers of aphasia research, such as Arnold Pick ${ }^{2}$ [4], it was Mesulam who proposed differentiating this syndrome from Alzheimer's disease, and thus revived interest in a clinical phenomenon that had been largely forgotten [5].

Mesulam [6] initially suggested the term 'slowly progressive aphasia' to characterize this form of progressive language deterioration. Subsequently, other terminologies have been proposed, including progressive aphasia without dementia, progressive non-fluent aphasia, and progressive language impairment without dementia.

Although these days researchers are in agreement that PPA constitutes a varied group of symptoms, the classification and diagnostic criteria of its individuals variants still remains a debateable question. Gorno-Tempini et al. [7] grouped criteria for the classification of PPA into the following clinical subtypes:

1. PPA-G (Agrammatic/ Nonfluent Subtype) - in which patients demonstrate a progressive deterioration in language.

Clinical diagnosis of the non-fluent/agrammatic variant of PPA could be made if at least one of the following cores is presented: a) agrammatism in language production; b) effortful, halting speech, with inconsistent speech sound errors, and at least two of the three following cores must be presented: 1) impaired comprehension of subsequent syntactically complex sentences, 2) impaired single word comprehension, 3) spared object knowledge.

1. Neuroimaging with CT, MRI, and SPECT are useful adjuncts confirming the diagnosis. PPA is a manifestation of fronto-temporal degeneration or Pick complex, which is probably the second most common degenerative dementia after $\mathrm{AD}[2]$.

2. Cases of patients with a relatively pure form of progressive speech disorders, usually accompanied by cortical atrophy in the area of the left frontal lobe and / or temporal, were first described by Arnold Pick [8] in 1892. His 69-year-old patient showed almost two years-old isolated symptoms of gradually worsening transcranial sensory aphasia.
Imaging-supported non-fluent/agrammatic variant of PPA diagnosis could be made if the following criteria are presented: a) clinical diagnosis of a non-fluent/agrammatic variant of PPA, b) imaging must show one or more of the following results: 1) predominant left posterior fronto-insular atrophy on MRI or 2) predominant left posterior frontoinsular hypoperfusion or hypometabolism on SPECT or PET.

Non-fluent/agrammatic variant PPA with definite pathology could be made if the patient has a clinical diagnosis (criterion 1 below) and either criterion 2 or 3 must be present: 1) clinical diagnosis evidence/agrammatic variant PPA, 2) histopathologic evidence of specific neurodegenerative pathology (e.g., FTLD-tau, FTLD-TPD, AD, and others), 3) presence of a known pathogenic mutation.

2. PPA-L (Logopenic Subtype): in which patients demonstrate a problem with single- word retrieval in spontaneous speech and naming in contrast to PPA-G.

Clinical diagnosis of logopenic variant PPA could be made if both the following core features are presented: a) single-word retrieval in spontaneous speech and naming, b) impaired repetition of sentences and phrases, and at least three of the following other features are presented: 1) speech (phonologic) errors in spontaneous speech and naming, 2) spared single-word comprehension and object knowledge, 3) spared motor speech, 4) absence of frank agrammatism.

Imaging-supported logopenic variant of PPA diagnosis could be made if the following criteria are presented:a) clinical diagnosis of a logopenic variant of PPA, b) imaging must show one or more of the following results: 1) predominant left posterior perisylvian or parietal atrophy on MRI, 2) or 3) predominant left posterior perisylvian or parietal hypoperfusion or hypometabolism on SPECT or PET.

Logopenic variant PPA with definite pathology could be made if the patient has clinical diagnosis (criterion 1 below) and either criterion 2 or 3 must be present: 1) clinical diagnosis evidence/logopenic variant PPA, 2) histopathologic evidence of specific neurodegenerative pathology (e.g., AD, FTLD-tau, FTLD-TPD, and others), 3) presence of a known pathogenic mutation.

3. PPA-S (Semantic Subtype): in which patients demonstrate a progressive deterioration of understanding words, especially nouns, and recognizing objects while other cognitive faculties remain remarkably spared.

A clinical diagnosis of semantic variant PPA could be made if both of the following core features are presented: a) impaired confrontation naming, b) impaired singleword comprehension, and at least three of the following other features are presented: 1) impaired object knowledge, particularly for low frequency or low familiarity items, 2) surface dyslexia or dysgraphia, 3) spared repetition, 4) spared speech production, grammar or motor speech.

An imaging-supported semantic variant of PPA diagnosis could be made if the following criteria are presented: a) clinical 
diagnosis of a semantic variant of PPA, b) imaging must show one or more of the following results: 1) predominant anterior temporal lobe atrophy on MRI, 2) or 3) predominant temporal lobe hypoperfusion or hypometabolism on SPECT or PET.

Logopenic variant PPA with definite pathology could be made if the patient has clinical diagnosis (criterion 1 below) and either criterion 2 or 3 must be present: 1) a clinical diagnosis of semantic variant PPA, 2) histopathologic evidence of specific neurodegenerative pathology (e.g., FTLD-tau, FTLD-TPD, AD, and others), 3) the presence of a known pathogenic mutation.

The non-fluent PPA variant accounts for about $20 \%$ of all people with fronto-temporal dementia. People with non-fluent PPA can display a variety of different language symptoms, and no two cases are exactly the same. As the disease progresses, communication is lost.

Therefore, AAC aids and devices might be used to enhance the communication.

\section{OBJECTIVE}

The aim of the study is to evaluate ACC in the improvement of non-verbal communication of a patient with a clinical and imaging-supported diagnosis of an isolated non-fluent/ agrammatic variant of primary progressive aphasia (PPA).

\section{CASE STUDY}

The patient was a 73-year-old retired teacher of Polish, a righthanded individual who until the onset of the illness had led an active social life. She checked into a neurological clinic for the first time in June 2008, complaining of headaches and difficulties in saying things. The doctor did not notice the manifestation of any neurological symptoms or disturbances in linguistic understanding including naming, repeating and spontaneous utterances. Also preserved were memory, visual perception, spatial orientation and logical thinking. The patient functioned well within everyday life.

The first step was to measure the patient's risk factors for $\mathrm{AD}$, using the MMSE [9]. She scored 24 points in this scale, and was examined further to determine whether there were other symptoms of AD.

The second step, was her diagnosis for potential AD on the basis of the NINCDS/ADRDA criteria [10]. None of these symptoms were discover. She did not display impaired repetition of sentences and phrases or speech (phonologic), errors in spontaneous speech and naming. Memory, visual perception, visual-spatial orientation and reasoning were not affected by the disease. She continued to function normally in daily life activities.

The third step was to evaluate the presence and intensity of vascular factors according to the modified Hachinski Scale [11] (Ha-mod) presented in Tab. 1.

She obtained a score of 1 point as a result of declared hypertension; she was therefore diagnosed as being without vascular aggravation. She also did not display any of the following exclusions criteria:
Table 1. Assessment of the intensity of vascular factors according to the Ha-mod

\begin{tabular}{ll}
\hline Assessed factor & Score \\
\hline Declared hypertension & 1 \\
\hline Stroke & 2 \\
\hline Symptoms of arteriosclerosis & 1 \\
\hline Neurological subjective symptoms & 2 \\
\hline Neurological focal symptoms & 2 \\
\hline Coronary heart disease & 1 \\
\hline Hypotension & 1 \\
\hline Heart rhythm disorders & 1 \\
\hline Diabetes & 1
\end{tabular}

Source: after Hachinski, [11]

$\checkmark$ clinical or radiological features that would suggest a vascular foundation for the disease;

$\checkmark$ affective disease, schizophrenia, alcoholism, drug or psychoactive substance addiction, epilepsy, Parkinson's disease, or an intellectual handicap;

$\checkmark$ disturbances of consciousness;

$\checkmark$ illnesses affecting the motor organs, vision or hearing, that could significantly impair her compliance with the commands and procedures included in the clinical scales being used;

$\checkmark$ other serious somatic diseases.

The fourth step was to evaluate her cognitive functions, at baseline and after 2, 4 and 6 years (the period between the baseline and the follow-up examinations ranged from 22-26 months) with the use of standard neuropsychological tests.

The pharmacotherapy being administered to the patient at the time was taken into account. Procognitive drugs and other psychotropic medicines administered for at least 14 days of constant treatment were noted. Information from the medical staff served to clarify the dosage of such drugs and the period of their administration.

The research methodology was fully accepted by the patient, who expressed in writing her full agreement to participate in the study. Permission to conduct this research was obtained from the local Bioethics Committee.

First year of the illness. Several months later, in January 2009, the patient again registered at a neurologist's due to a gradual intensification in difficulties in speaking. There appeared in her utterances disturbance in sentence order as well as an incorrect use of phrases. Often these were exchanges in the use of words from the same semantic category (e.g., 'pear' instead of 'apple', 'spoon' instead of 'fork' and 'table' instead of 'chair'). She also used words that were mispronounced or incomprehensible (e.g.,'track' for 'truck'), and talking around a word (e.g., 'We went to the place where you can get milk' for 'grocery store'). Comprehension of everyday conversational speech was well preserved, and formal testing demonstrated only mild abnormalities. Present sporadically were contaminations, e.g., cyclist rider (cyclist + bike rider). The understanding of everyday utterances was well preserved, and in formal research only insignificant disturbances were noted. At this stage, no disturbances in writing and reading had appeared (Tab. 2). 
Second stage of the disease. In September 2011, (three years after falling ill) clear symptoms of aphasia and mild dysgraphia were noted in the patient. The patient switched the order of words in sentences in both speech and writing. Quite often there appeared phonetic distortions of words as well as their use in an opposite meaning (e.g., 'he' for 'she' or 'yes' for 'no'). Word understanding was still preserved, but sentence comprehension suffered if the sentences were long and grammatically complex. There were also disturbances in repetition, particularly in longer sentences and polysyllabic words. It was possible but difficult to establish verbal contact with the patient. Spontaneous bouts of speech displayed increased difficulty in pronouncing certain words, and to turn some words to others. Sentences became gradually shorter and word-finding hesitations became more frequent, occasionally giving the impression of stammering or stuttering. Pronouns, conjunctions and articles were lost first. Episodic memory and reasoning, visual perception, visual-spatial orientation (Fig. 1 B) were still not affected by the disease.

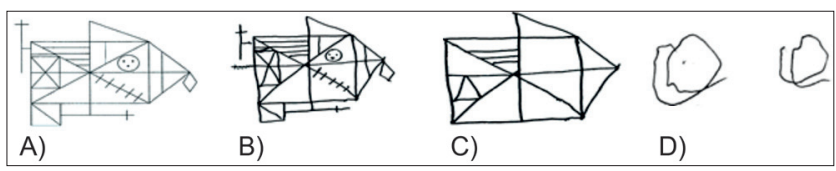

Figure 1. Rey-Osterrieth complex drawing. A) model; B) figure made in the study during the first year (a year after falling ill); C) drawing made in the second study (three years after falling ill), D) drawing made in the third study five years after falling ill)

The comprehension of everyday conversational speech was still well preserved, and the patient was still able to function normally in daily life activities.
Although in neuropsychological testing the patient demonstrated moderate abnormalities (Tab. 2). The appearance of difficulties in the construction and understanding of longer sentences were noted. The patient constructed only short sentences in which there was often an absence of pronouns, prepositions and conjunctions (connectives). Difficulties in finding word equivalents became intensified, which resulted in the impression of stammering and stuttering. In the patient's spontaneous utterances there occurred numerous distortions in words, as well as agrammatisms resulting from the incorrect use of inflection in grammatical endings. For example, in response to the question in Polish: 'Ile pani ma dzieci' [How many children do you have?], the patient replied: 'dwa synu' [two sons, yet with the incorrect suffix ' $u$ ' for the plural form of the noun 'sons' and the incorrect choice of the numeral 'two' - here given in the nominative case as opposed to the genitive], and when asked where she was going, her reply: 'do doma' showed her inability to remember the correct construction wherein ' $u$ ' constitutes the ending for the Polish word 'dom' [house/home] replacing this with the ungrammatical 'a'. As a measure of the disease's development was the intensification of initially echolalia and subsequently palilalia. ${ }^{3}$ Within the course of an eight-minute recording of the patient's speech it was possible to understand only 12 short words uttered by her (Pan, mama, daj [You/he (3rd person singular pronoun: male formal polite), mummy, give (imperative)]). It was additionally noted that echolalia occurred. The patient would quite often unintentionally repeat her own words (pewnie...pewnie... pewnie) or syllables (e.g., a ja.. ja... a ja... a ide, a do domu... do do domu... a ja... do domu...). Equally present were other perseverations of the initial syllable which,

Table 2. Disturbances in the constructing of the patient A.G.'s utterances

\begin{tabular}{|c|c|c|c|c|}
\hline No. & Doctor's question & Patient's answer & Meaning & Disturbance \\
\hline \multicolumn{5}{|c|}{ First stage of the disease } \\
\hline 1. & What do you? & Jestem renta nauczycielka [l teacher retired] & I am a retired teacher & reordering of words \\
\hline \multicolumn{5}{|c|}{ Second stage of the disease } \\
\hline 2. & $\begin{array}{l}\text { Are you afraid (frightened) of } \\
\text { anything? }\end{array}$ & Boiła piese... [I frittened av degs...] & $\begin{array}{l}\text { I'm afraid (frightened) } \\
\text { of dogs }\end{array}$ & $\begin{array}{l}\text { agrammatism + omission of the } \\
\text { function word }\end{array}$ \\
\hline 3. & What do you do? & Co pani robi? [What do you do?] Co pani robi? [What do you do?] & educate & echolalia \\
\hline 4. & Have you had a cold? & $\begin{array}{l}\text { Przeziębiewiona... [colded...] Przeziębiewiona... [colded] [a } \\
\text { break in the utterance] } \\
\text { hroat (pointing to her throat) }\end{array}$ & & echolalia and word distortion \\
\hline 5. & $\begin{array}{l}\text { What do you write with/what } \\
\text { are you writing with? }\end{array}$ & $\begin{array}{l}\text { and you... write... and write.. you write... and write... and } \\
\text { write }\end{array}$ & $\begin{array}{l}\text { I'm writing with a pencil/ } \\
\text { I write with a pencil }\end{array}$ & Echolalia + palilalia \\
\hline 6. & Where are you going? & $\begin{array}{l}\text { and mee.. and mee } \ldots \text { and mee... and } I \ldots \text { and ggo... and } \\
\text { ggo... and to to house... to to house. }\end{array}$ & I'm going home & $\begin{array}{l}\text { palilalia } \\
+ \text { agrammatism }\end{array}$ \\
\hline \multicolumn{5}{|c|}{ Third stage of the disease } \\
\hline 7. & Do you have an identity card? & $\begin{array}{l}\text { Osi... osi... Oho... oho... ho... osis... osis... ohehehe... } \\
\text { [she writes] }\end{array}$ & I do & $\begin{array}{l}\text { permanent semantic signals* } \\
\text { + quasi-pathological laughter }\end{array}$ \\
\hline \multicolumn{5}{|c|}{ The muteness phase } \\
\hline 8 & $\begin{array}{l}\text { Do you like rhubarb cake/pie/ } \\
\text { tart? }\end{array}$ & $\begin{array}{l}\text { Sighing Oh... Oh... } \\
\text { [absence of mimicry and a nodding head] }\end{array}$ & Yes & appeal signals \\
\hline \multicolumn{5}{|c|}{ After the introduction of the AAC system } \\
\hline 9 & $\begin{array}{l}\text { Would you like something to } \\
\text { drink? }\end{array}$ & $\begin{array}{l}\text { Oho...oho... ho... osis... osis [as well as a gesture pointing to } \\
\text { a mug] }\end{array}$ & & $\begin{array}{l}\text { variable semantic signals + quasi- } \\
\text { pathological laughter }\end{array}$ \\
\hline 10 & Would you like me to sing? & $\begin{array}{l}\text { Sssssss..... sssssssss.... } \\
+ \text { a gesture indicating the therapist }\end{array}$ & Yes & variable semantic signals \\
\hline
\end{tabular}

3. Palilalia - a symptom involving the involuntary repetition of one's own words or syllables [1 
however, was difficult to evaluate as to whether it belonged to palilalia or perseveration. At this stage, motor activity disturbance had not yet occurred, but it was possible to observe the first symptoms of a slowing down in finger movement and the manifestations of mild apraxia. However, there was no connection with the PPA diagnosis.

Beside the difficulties in speaking there also appeared problems in the understanding of longer utterances. The patient repeated simple sentences, yet was unable to repeat longer, compound and complex ones. She was also unable to repeat compound words, merely the function words (without - if - none - or). At this stage, there also appeared echolalia ${ }^{4}$ particularly in replies to the researcher's questions. In addition, the repeated words were often distorted as illustrated by the example given. The patient, in reply to the neurologist's question: Czy jest Pani przeziębiona? [Do you have a cold?] answered „przeziębiewiona... przeziębiewiona [colded...colded] (cf. Tab. 2). This answer not only indicated a manifestation of echolalia but also difficulties in articulation of an apraxia nature. It is also another example of the overlap of symptoms and the diagnostic difficulties associated with it. Interpretation difficulties may also be caused by the fact that after a certain time the patient did answer the question she had been asked by saying "garda" [hroat] wherein she pointed to her throat. One could therefore doubt whether this is in fact echololia, but the amount of time that had passed from the asking of the question indicates that she had understood it only after the elapsing of more than three minutes. Such a phenomenon may be observed frequently with brain damage, where it is connected to destabilisation of the brain's systems connected with it. It follows that it should additionally be noted here that echolalia in its pure form also appeared in other utterances of the patient. For example, in response to the question 'What are you writing with?' the patient replied: 'and you... write... and write.. you write... and write... and write.'

Maintaining of the conversation flow was disturbed, even though the patient's hearing was normal. This resulted from difficulties in finding the correct words, with a constant forgetting of the names of objects, animals and the names of people. There also occurred difficulties in reading which could, however, be a manifestation of the above-mentioned difficulties in articulation. For example, the patient in reading the text given, read out the words 'mózgu' [of the brain] as 'musku' [of Brian] and 'zawroty głowy' [head dizziness] as 'zowroty gowy' [heed dozziness]. Therefore, we are dealing here with a devoicing of vowels and an omission of vowels difficult to articulate. There also appeared problems with counting. This was to manifest itself, among other situations, with evaluating the amount of change while shopping.

The patient was still able to note down sentences spontaneously chosen by herself, although she did not complete within them the final word (cf. Fig. 2A). She also had a retained episodic memory (!).

\begin{tabular}{|c|c|c|c|}
\hline 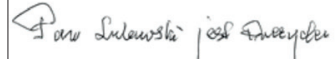 & Anveryclen & Andrue & Heoreds \\
\hline A) & B) & C) & D) \\
\hline
\end{tabular}

Figure 2. Patient's attempts at writing during various stages of the disease. A) a year after falling ill; B) three years after the illness; C) five years after the illness), D) six years after the illness [after 20 ACC therapy]

4. Echolalia - thought disturbance manifesting itself as the unnecessary repetition of words or phrases uttered by someone else.
Brain MR showed an asymmetric focal atrophy predominant in the left posterior fronto-insular region (Fig. 3 A, B, C).

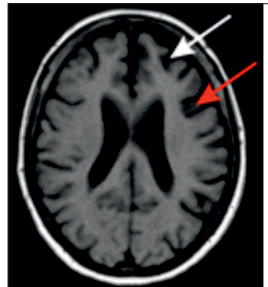

A)

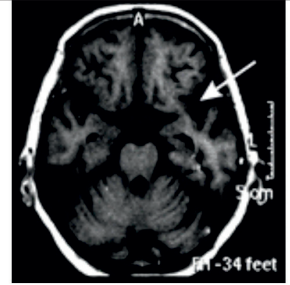

B)

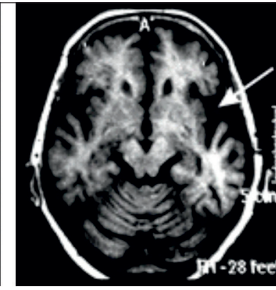

C)
Figure 3. Brain MRI in 2011: SET1 sequence, axial plane

A - cortical atrophy of the left superior frontal gyrus (white arrow) and left interior frontal gyrus (red arrow).

B - left side insular temporal operculum atrophy at the suprasellar cistern level (white arrow).

C - left side insular temporal operculum atrophy at the midbrain level (white arrow).

To sum up, we can confirm clinical diagnosis of a nonfluent/agrammatic variant of PPA, and an imaging-supported non-fluent/agrammatic variant of PPA diagnosis because the imaging findings show a predominant left posterior frontoinsular atrophy on MRI, as suggested by Gorno-Tempini et al. [7].

An overall assessment of cognitive function (screening), divided into intellectual functions, memory, visual spatial functions, language functions and general characteristics of dementia are shown in Table 3.

Table 3. Results obtained from patient A.G. during standard neuropsychological tests after admission (examination I), after 1 year of treatment (examination II), after three years of treatment (examination III), after five years of treatment (examination IV)

\begin{tabular}{lcccccc}
\hline \multirow{2}{*}{ Test } & Scale & \multicolumn{5}{c}{ Results } \\
\cline { 3 - 6 } & & Wechsler Adult Intelligence & Scale- Revised (WAIS-R) \\
\hline I.Q Global & 100 & 109.0 & 38.5 & - & - \\
\hline I.Q Verbal & 100 & 111.0 & 19.0 & - & - \\
\hline I.Q Non-verbal & 100 & 107.0 & 58.0 & - & - \\
\hline \multicolumn{6}{c}{ Wechsler Memory Test - IIII } & \\
\hline
\end{tabular}

\begin{tabular}{|c|c|c|c|c|c|}
\hline $\begin{array}{l}\text { Logical memory - immediate } \\
\text { reproduction }\end{array}$ & 24 & 23.0 & 16.7 & - & \\
\hline $\begin{array}{l}\text { Logical memory - delayed } \\
\text { reproduction }\end{array}$ & 24 & 21.0 & 9.4 & - & - \\
\hline $\begin{array}{l}\text { Visual memory - immediate } \\
\text { reproduction }\end{array}$ & 41 & 39.5 & 30.2 & - & - \\
\hline $\begin{array}{l}\text { Visual memory - delayed } \\
\text { reproduction }\end{array}$ & 41 & 37 & 22 & - & - \\
\hline Token Test & 50 & 2 & 18 & - & - \\
\hline Boston Naming Test-revised & 60 & 56 & 34 & 1 & - \\
\hline \multicolumn{6}{|c|}{ Language functions - WAB [3] } \\
\hline WAB - AQ & 100 & 97.0 & 37.0 & 21.0 & - \\
\hline WAB - CQ & 100 & 94.0 & 86.0 & 63.0 & - \\
\hline \multicolumn{6}{|c|}{ Process time } \\
\hline Reaction time (sec.) & 100 & 5 & 270 & 320 & - \\
\hline Preservations & $\begin{array}{l}\min 0- \\
\max 20\end{array}$ & 3 & 9 & 10 & - \\
\hline
\end{tabular}

Preservations

General mental functioning

MMSE

$\begin{array}{lll}30 & 24 & 19\end{array}$

[1] WAIS - R Wechsler Adult Intelligence Scale. 2] WMS-III - Wechsler Memory Scale - III. [3] WAB -Western Aphasia Battery: AQ = Aphasia Quotient; $C Q$ = Cortical Quotient [12] 
Intellectual functions. An analysis of the results obtained in the WAIS-R intelligence test allowed one to state that in Test (examination) 1 the patient obtained a profile of disturbances of a language nature. This profile is different than for those with a PPA logopenic variant where, on the first plane, there emerge spatial-visual deficits connected more with the non-verbal functions that appear in the WAIS-R test. In Tests 2 and 3, there occurred significantly intensified difficulties connected with completing verbal tasks, and insignificant difficulties with the completion of non-verbal task.

Memory. In the WMS-III test the appearance of mild disturbances to logical memory was noted. Greater memory disturbances were not noted in Test 1. In Tests 2 and 3, disturbances to memory gradually increased, wherein the greatest difficulties occurred during the completion of tasks, with a delay. It is worth noting the fact that the patient obtained much worse results in relation to aural memory than with visual. In reconstruction with a delay much lower results were obtained, although sizeable portions of information were remembered. It is also worth noting that emotional memory was still maintained. It was observed that the patient started to cry when the tester asked about her son Artur, and pointed to his photograph. Her son had died tragically at the age of 23 in a car accident.

Visual-spatial functions. In the Benton Orientation Line Test, as equally in the Face Recognition Test, there occurred slight disturbances, as anticipated. These results are within the boundaries of the norm, and explain the observation made during the conducting of the tests. It may be noted that the patient sometimes abandoned a task and did not finish it, something that may lower the results within the scope of sight-spatial functions. These disturbances may also be connected with deficiencies in attention selectivity, whereby the patient devotes noticeably less time to the completion of particular tasks. In Tests 2 and 3, a gradual intensification in disturbances was noted which, however, had a different profile than in the case of individuals with a logopenic PPA variant.

Language functions. In the Western Aphasia Battery (WAB), the appearance of speech disturbances of the aphasia type was noted - Aphasia Quotient (AQ) was 64.3. The opposite profile was somewhat surprising: on the Cortical Quotient (CQ) for the patient under description $=68.6$. The reason for this is more than likely the fact that the calculation of this indicator takes into consideration the results of image recognition which, as we know, may be disturbed in patients with dementia of the Alzheimer type. In Tests 2 and 3, the aphasia quotient (AQ) increased quickly and significantly slower the Cortical Quotient (CQ). The escalation of these disturbances, however, has a different profile than in those with a logopenic PPA variant.

Slowness and general features of dementia. In the first test the patient was energetic and carried out the cognitive tasks quickly. The reaction time was 5 seconds. In the second and third test, slowness significantly increased in the reaction time - 279 and 320 seconds, respectively. The motor perseveration also intensified with the course of the disease, something that was chiefly noted in writing.
In the MMSE test, the patient obtained in the first test 24 points, which represents Mild Cognitive Impairment (MCI). In the second test, the results were lower - 19 points; however, this was the so-called MMSE linguistic profile. In the third test, there was observed a dramatic increase in the general features of dementia. As a result of the deepening problems with speech and the appearance of incomprehensible utterances, the patient was placed under the fulltime care of a third party. She experienced significant difficulties in contact with her surroundings as she was unable to speak. Her social functioning underwent a significant deterioration.

Third stage of the disease. In August 2013, five years from the onset of the disease, the patient entered the third stage of the disease. Incomprehensible utterances, limitations in contact with her surroundings and a withdrawal from playing full social roles and engagement in social tasks were observed. The patient was no longer able to communicate verbally with her carer or doctor. She was also unable to say her name or surname, or that of her son. She would answer every question asked with the meaningless words: 'osis... osis'. She communicated in writing and through gesticulation. In writing, there was noted the appearance of dysgraphia mistakes. A characteristic feature, besides an alteration of letters, was the failure to complete sentences and words (cf. Fig. 2 B and C). Disturbance in other cognitive functions were also experienced. The patient displayed definite difficulties in understanding what others said. She equally did not understand texts she herself had read.

The mutism phase. The complete loss in the ability to communicate occurred in September 2014. The failure to say anything was accompanied by a growth in pathological vocalisation, which became the only way of reaction to the questions asked of the patient. These vocalisations resembling a pathological laugh ${ }^{5}$ and appeared regardless of the context in an totally automated way. This enabled the patient to function normally. Writing ability was maintained for a relatively long time, although dysgraphia involving the rearrangement of letters appeared (cf. Fig. 2C). From the beginning of 2015 (seven years after the disease's onset), the patient was already unable to write as a result of difficulties in starting the activity.

Application of the Alternative System of Communication (AAC). The Alternative System of Communication System (AAC) is used with the aim of improving the quality of life for patients devoid of speech. It must be remembered, however, that the need to apply utilised aids is within an appropriate context and are appropriate for the requirements of the given patient. Taking this into consideration, the following techniques were applied:

1) a system of unaided communication - in which so-called body language is used. These are gestures and a system of appropriate signs;

2) a system of aided communication - here are utilised special boards and a set of images and letters, enabling the patient to construct utterance transmissions. At present, these are also used in an electronic form.

5. This laughter was abnormal in quality, often shrill and uncoordinated, and did not have the 'infectious' property of normal laughter. 
There as prepared for the patient a system of alternative communication, including response charts (YES / NO) written in large letters (Fig. 4), and a set of 10 arrays of communication set within the basic sectors of everyday activities (in bed, washing, combing, dressing, eating, drinking, personal hygiene, toilet requirements, everyday objects, including the telephone, and treatment (Fig. 5).

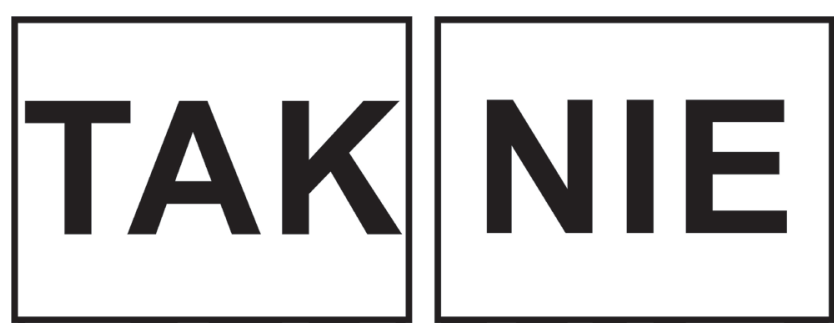

Figure 4. Set of Yes / No Alternative System of communication. Source: M. Pąchalska [13], with the permission of the author

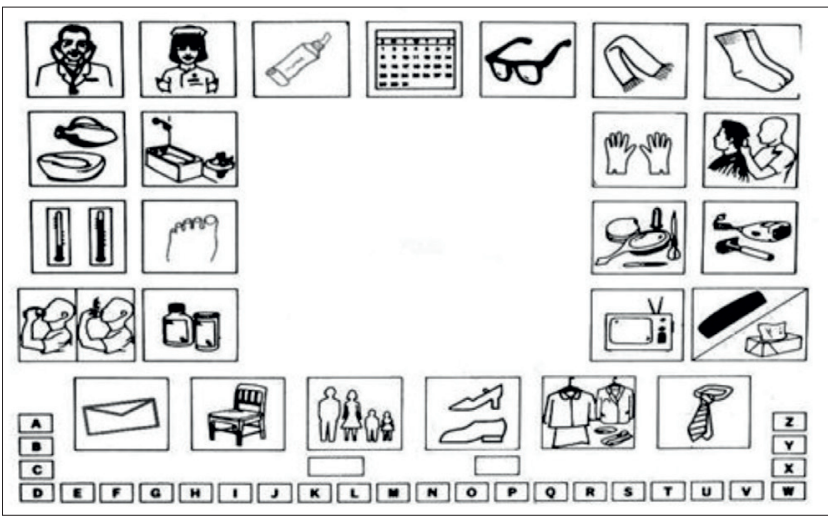

Figure 5. Sample Communication Table containing symbols from the Alternative System of Communication.

Source: M. Pąchalska [13], with the author's permission

A good example of the use of the alternative communication system is the use of a communication board entitled 'Food' and an indication of those activities related to drinking in a situation where she wanted her son to prepare tea for her (Fig. 6A), and additionally the placing of the word 'drink' (Fig. 6B), or the use of the board entitled: Personal Care, and the patient's indication of washing in a situation where she felt that her nappy was wet.

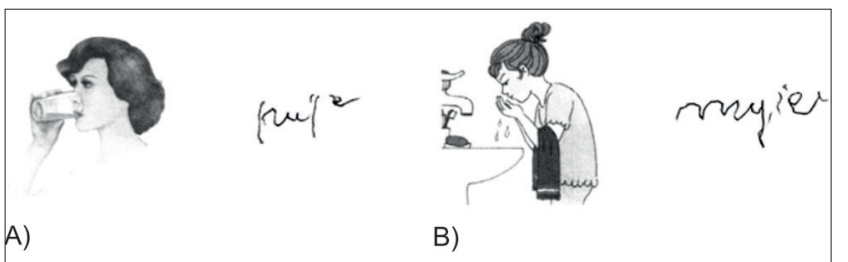

Figure 6. Examples of ways of non-verbal communication in conjunction with writing, using the Communication Boards containing a set of actions with an alternative system of communication.

Source: M. Pąchalska, [13], with the permission of the author.

To choose the theme of communication special Communication Boards have been developed (Fig. 7).

A good example of using boards of communication was the selection by the patient of the topic of conversation. The patient pointed to a picture of the family, and right next to it

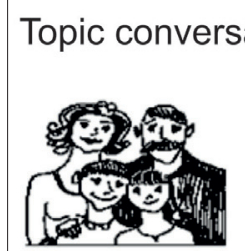

Family

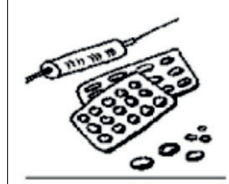

Medicaments

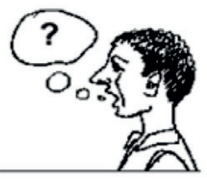

Speech

therapy

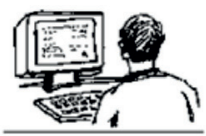

Work

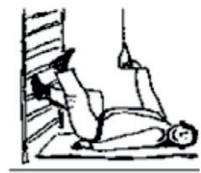

Physical therapy

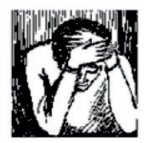

Worries
Figure 7. One of the communication boards: Select a topic of conversation. Source: Pąchalska [13], with the permission of the author

wrote the name of her son Andrew. This situation resulted in the appearance of the son and a few questions, one of which was: 'Are you glad that I came?' The patient pointed to the word YES and wrote in addition to the word 'yes'.

After 20 ACC therapy sessions the patient again started to write, although she did this sporadically. The first letter of the word was most often correct; however, subsequent letters were rearranged and difficult to decipher as a result of the accompanying perseverations. For example, the name of her son 'Andrzej' she wrote as 'Adeareee' (cf. Fig. 2C).

At this stage, in attempts to draw a clock face, in which there had been noted from the beginning of the disease errors of a language nature (cf. Fig 8A and B), there was noted a return of the ability to write numerals. The patient wrote on the right side of the clock face the figures $1,2,3,4,5$, while from the centre of the clock in the bottom the figures $6,7,8,9$. The numeral 10 was placed correctly on the clock face, it was written, however, as a perseveration of s's and spirals (cf. Fig. 8 D).

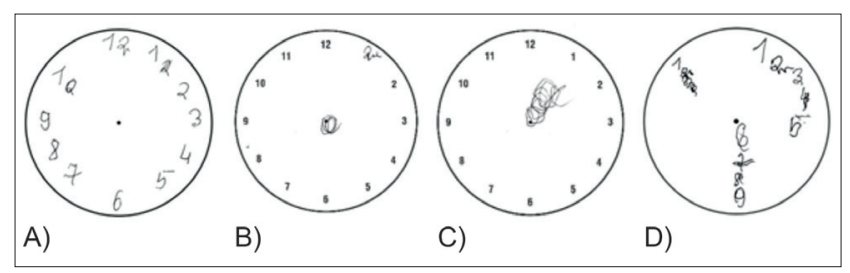

Figure 8. Attempts at drawing a clock face by the patient at various stages of the disease. A) a year after the onset of the illness; B) three years after the onset of the illness; C) five years after the onset of the illness; D) six years after the onset of the illness [after 20 sessions of ACC therapy]

Of especial note is the return of the ability to indicate correctly the six primary colours and being able to write down the names of three colours: green, yellow and navy blue (cf. Fig 9). The first, and sometimes the second and even the third letters, were written correctly. However, one can observe disturbances connected with mistaking letters, agrammatism, as well as the incorrect writing of letters.

The results obtained in the Non-verbal Communication Scale, after 20 sessions of the use of ACC, are illustrated in Figure 10.

One can note that as a result of the application of AAC therapy, the quantity of non-verbal ways of communication increased. The greatest improvement concerned drawing, 


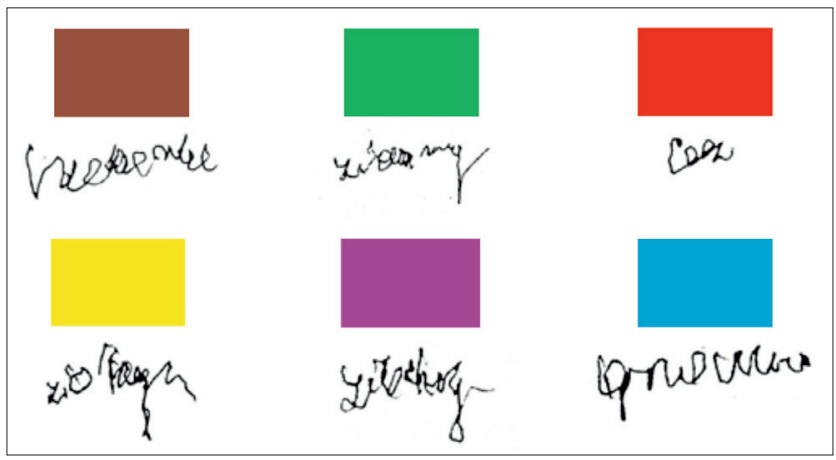

Figure 9. Indicating and writing of 6 primary colours

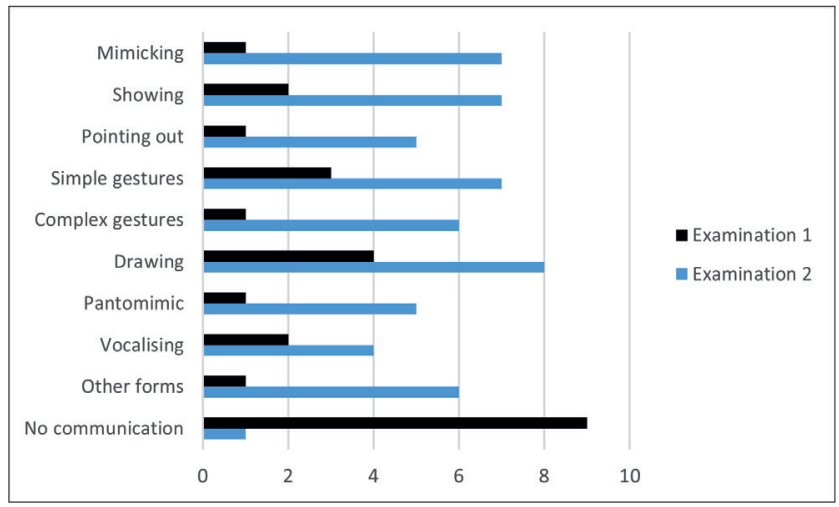

Figure 10. Results obtained in the Non-verbal Communication Scale, before (examination 1) and after 20 sessions of the use of ACC (Examination 2)

communicating by means of mimicry, simple gestures, pantomime gestures or pointing.

Gesture communication with family and carers. 20 sessions were conducted which covered exercises in communicating with the use of simple aids. As a result of this training, the patient possessed the ability to non-verbally communicate with her son and with the personnel at the care home. There also occurred simultaneously a clear improvement in the patient's functioning in everyday life.

\section{DISCUSSION}

The results presented above, obtained during a longitudinal course from a patient with an initial non-fluent agrammatical occurring aphasia (PPA-G), confirm the widely observed jointly occurring disturbances in patients with frontotemporal dementia. This constitutes a serious diagnostic problem and often leads to a mistaken diagnosis. As has been pointed out many times, the best solution is the combination of diagnosis with therapeutic interaction. This creates the possibility to become acquainted with the patient and their problems, including equally the disturbances that occur as well as those possibilities the patient still retains. This enables the observation of the exact specifics of the disturbances syndrome and often leads to a reappraisal of the earlier diagnosis $[1,14,15]$. The necessity for a detailed acquaintance with the patient results equally from the changeability observed in these cases to the symptoms connected with their general state.

In the case of fronto-temporal dementia, the picture of the observed symptoms depends to a large degree on the stage of the disease, because with the flow of time there occurs a gradual worsening in the patient's state. It happens that earlier symptoms disappear and new ones appear, resulting in the complete alteration of the picture of the disease. In the case of the initial appearing aphasia, the end manifestation is mutism, as pointed to by a number of authors [16]. It follows, however, to emphasise that mutism is a process, and that like every other brain process is characterised by a variable dynamic and course. We can talk about various stages of mutism depending on the patient's consciousness (cf. Fig. 11). State A represents full consciousness and preserved ability to communicate. In state B, the patient, to a significant degree, has a preserved consciousness (awareness), but in practice is already unable to utilise a linguistic verbal form of communication. However, limited possibilities for non-verbal communication still remain. In some patients there is still preserved the ability for written communication, although this written input displays numerous mistakes. In state $\mathrm{C}$, the patient has an extremely limited consciousness as well as there occurring a complete inability to communicate. It should be noted, however, that the borders between these states are fluid, which results in the possibility of differentiating other substages.

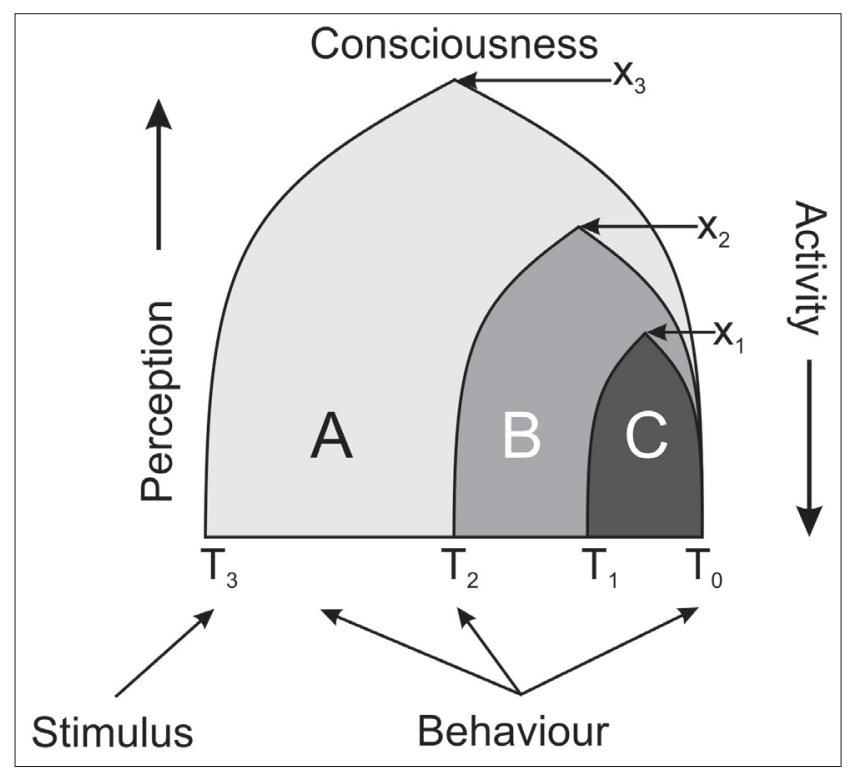

Figure 11. Dynamics in the course of mutism depending on the degree of consciousness retained

As pointed out in the Introduction, mutism is a manifestation of resignation from undertaking attempts at communicating with one's surroundings when these attempts end in failure. Families and doctors often interpret attempts of this type as symptoms of pathological vocalisation. As a rule, in the subject literature it is noted that in patients with initially occurring aphasia the appearance of many forms of pathological vocalisation is observed in the later stage of the disease, such as shouting, singing, chanting, grunting and mumbling. Here, it is emphasised that the vocalisations are automatic and stereotypical in character. Equally is shown the appearance of pathological laughter, emphasising that as the disease develops this laughter remains the only form of vocalisation [17].

In her book devoted to communication amongst children with autism, Katarzyna Markiewicz gives examples of wrong 
interpretations of patient behaviour on the part of doctors and therapists. Many types of behaviour evaluated as pathological and stereotypical have a specific meaning which the child's parents are able to interpret. This may be, for example, be nodding as a sign of boredom, or banging one's head on a table as a sign of protest [18].

In the patient described above the introduction of a system of alternative communication enabled her to forge contacts with her surroundings. As a result, there also appeared attempts at an initiation of contact; this does not simply refer to the help given to her along with gestures, but equally attempts at utterances themselves. These were obviously only simple sounds, for example, the uttering of a string of 'sy sy $s y$ ' combined with, as a rule, a pointing gesture. There also reappeared expressive words recalling a smile. However, it is characteristic that they appeared during attempts to forge contact, or as a reaction to questions asked of the patient. Consequently, this is not a pathological smile in the full meaning of the word.

It is worth noting here that the present - post therapy way in which the patient communicates is reminiscent of the communication of a small child prior to the mastering of speech, in the period which Leon Kaczmarek [19] has termed the period of melody. A small child also uses at this stage vocalisations which are comprehensible only for its immediate environment and it produces a series of sounds on which it imposes a specific meaning. These utterances are accompanied by gestures which enable one to understand the child's intentions, in a similar way to the situation in the case of the patient in the presented study. Therefore, it is important to mention here Kaczmark's classification of signals of this type. We use the term signal when it represents a definite sign sent intentionally by the sender with the aim of stimulating a desired (on the part of the sender) reaction in the recipient.

At the stage of melody the child uses the following signals, which we have presented in the order of their appearance in the child's utterances:

1. natural non-linguistic signal appeals: crying, shouting;

2. acquired non-linguistic signal appeals: cries, moaning, a series of vowels;

3. situational non-linguistic semantic signals - having a definite meaning:

a) variable;

b) permanent.

In order to make it easier for the reader to understand the nature of these signals we will present examples drawn from the book Nasze dziecko uczy sie mowy [Our child is learning to talk] [19].

Appeal signals are signals designed to attract the recipient's attention to a specific phenomenon. In a small child, this role may be performed by crying which informs its mother that it is hungry or cold. This is a natural signal. Acquired signals are various kinds of a child's vocalisation, those closely connected with a definite situation. For example, in Polish the utterance ' $y$ - $y$ - $y$ or $e-e-e$ ', showing with a finger what is being asked for results in a ' $h y$ ' and a climbing up on the carer's knee expressing a request to be taken into their arms, or smacking one's lips at the sight of food. These signals are accompanied by suitable gestures, making them comprehensible for their surroundings.

At the next stage of language learning, the child utilises non-linguistic situational semantic signals, the form and content of which undergo change in relation to the existing system. It happens that in Polish ' $h e$ ', ' $h y$ ' or ' $h e j$ ' are used interchangeably to emphasise that the child wants to drink something, or that it does not like something, etc.; and in this case, suitable gestures such as reaching out for a cup enable the carers to understand the child's intentions.

Constant semantic signals have an already established phonetic (sound) form (structure), but their content may be subject to changes. For example, a child saying in Polish ' $m a-m y$-me' and showing where something is located, or that it wants to be given something.

As we have already shown, the ways of communicating by the discussed patient following the introduction of an alternative system of therapy is reminiscent of the signals used by a child during the period of melody. They have also a situational character and are aided by gestures; however, they are not accompanied by a rich melody as characteristic for a child's utterance. Therefore, it is difficult to unequivocally classify although it undoubtedly constitutes attempts to establish contact with one's surroundings. Attention was brought by the world renowned linguist Roman Jakobson [20] to the similarity of aphasic disturbances, that is the breakdown of linguistic functions, to their acquisition. Despite certain similarities this is not the mirror reflection assumed by the academic, which has meant that his theory has been forgotten. As we have already shown, there occur as a rule in the case of pathology new symptoms - ones different from the norm, for onto older ontogenetic forms of behaviour there are played newly acquired forms of behaviour $[21,22]$. It is therefore difficult to expect the breakdown of a given function to take an identical course to that which saw its acquisition.

A microgenetic interpretation of symptoms. References to the process of the forming of the symptom within dementia may be helpful in explaining the disturbances observed in the patient described. It follows that this relates to the synchronic model of memory based on the principle of microgenetic theory, where it is the very disturbances of this process that lie at the bases of dementia (Fig. 12).

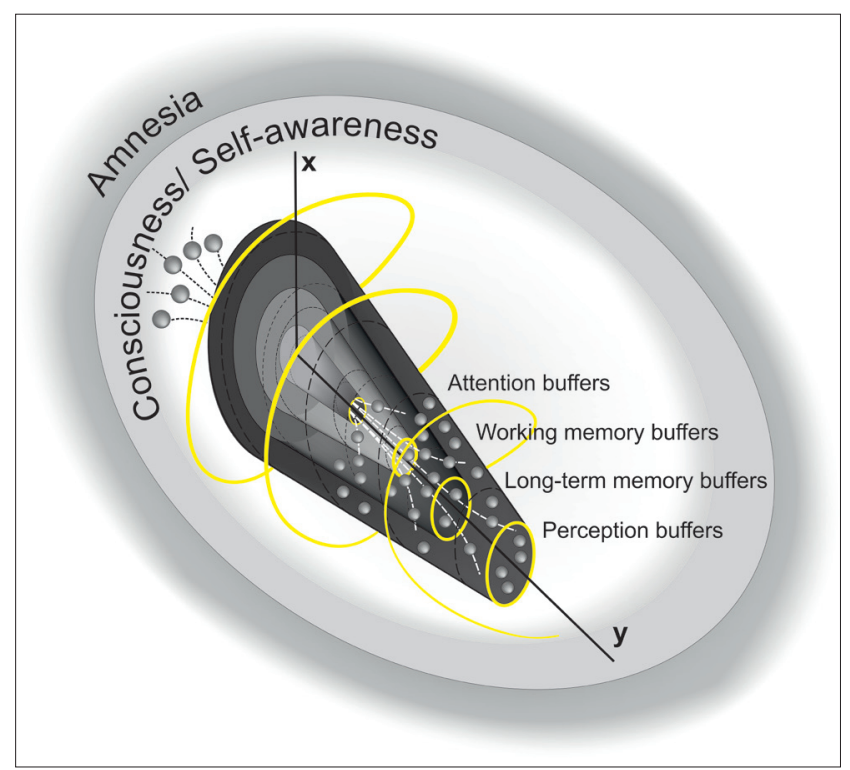

Figure 12. Synchronic model of memory (explanation in the text). Source: Pąchalska, Kaczmarek \& Kropotov [1], with modification) 
The model refers to the holographic model of the universe which, according to Peat [23], confirms the synchronicity of reality. The spatial configuration of the model makes it possible to present, on the $\mathrm{x}$ and $\mathrm{y}$ axes, the relationship between the overall structure of the attention and memory systems in terms of the number, content, and complexity of the elements being processed, and the time needed to complete the processing. It is assumed, following Pribram [23], that by changing the angle at which light beams from two lasers operate on a photographic image, one can obtain multiple images on the same surface. Thus, the synchronic pattern of the model (the dotted lines) reflects the holographic interaction of waves, corresponding to what happens in the brain: the pulsing of mental states and neuroplasticity (changes in neuronal connections and new connections in the brain) [24].

Consciousness and self-consciousness have been represented here as a separate circle, since this is what conditions the existence of cognitive processes, including memory and emotional processes. The outside (yellow) spiral refers to the fractal concept of consciousness and self-consciousness in relation to the mind, and to the synchronic image of reality formed by the self in relation to the world and the universe.

The tunnels through which the small spheres are flowing reflect different kinds of working and long-term memory, which allow the individual to form his/her own, synchronic reality, in the self-to-world relationship. Thanks to plasticity and new connections in the brain, a form of dependency is created between events, in which every causal connection is possible. The large yellow spheres are the buffers of 1) attention, 2) working memory, 3) long-term memory, and 4) perception.

When dementia begins to develop, the cognitive systems are destabilized. Dementia cannot contribute anything new to behaviour, but rather affects behaviour by removing essential components. The famous Soviet neuropsychologist A.R. Luria [15] stated that damage to the brain leads to a certain splitting of the layers of behaviour, which makes it possible to see into its deeper structure [25]. The particular activities comprising its components, which in normal behaviour occur without visible effort, are revealed. This can be seen most clearly in disturbances of speech, where we can observe difficulties in forming or comprehending utterances, or word-finding problems.

Luria [15] proved that a dynamic system of this sort can be easily destabilized. We observe this, for example, in a state of extreme fatigue, or when falling asleep, or by one's own volition when using psychoactive substances, of which alcohol is the most common. Another example of a more serious threat to the system's stability would be the consequences of a neurodegenerative disease. This happens because brain damage not only changes the existing connections, but also imposes new rules for functioning on the existing systems. In biological terms, this is manifested by neurological and cognitive disturbances; in social terms, by the patient's inability to function in the previous social roles; and in personal terms, by personality changes.

At a certain stage in the development of a neurodegenerative disease, especially in the cases of Primary Progressive Aphasia (PPA), the complex system of neuronal connections undergoes destabilization, linked to language functions with the relative preservation of other functions (cf. Fig 13). Always, however, disturbance in the functioning of one system, to a lesser or greater degree, will disturb the work of others, as a result of the network of existing connections. As presented in Figure 13, both emotions and the closely connected control over behaviour linked to them play a significant role in the modelling of a given patient's behaviour. This reflects the strict link between emotions and behaviour.

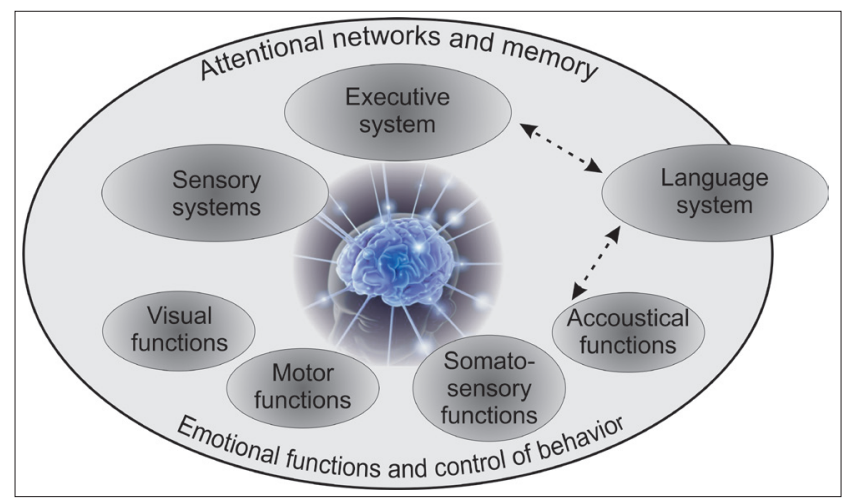

Figure 13. Destabilisation of the brain system as a result of a severing of neuronal links in patients with neurodegenerative diseases. It should be noted that there exist in the brain an entire, most complex network of neuronal connections between individual systems. The arrows shown on the diagram are consequently merely a simplification which should allow the reader to grasp the nature of existing connections

The destabilisation of this system can also be observed in states of fatigue, when falling asleep or in states induced by the drinking of alcohol. Obviously, the most important state of destabilisation occurs in cases of neurodegenerative diseases, when there occurs a severing of hitherto connections. This creates the need to completely rebuild the given system, something which interferes with its previous functioning. This finds reflection in neurological and cognitive disturbances and leads to a patient's social degradation and serious changes to the personality.

The process of destabilisation in brain systems creates diagnostic problems, for the same pathomechanism can manifest itself in a different form, depending on the task set for the patient. Consequently, individual researchers may observe the appearance of other, different symptoms, as is the case with damages to the frontal lobes [26-31].

The introduction of the Augmentative and Alternative Communication (AAC) system is conducive to a partial improvement in the stabilisation of brain systems, as it is conducive not only for the regaining of an ability to communicate, but also for the restoration of social bonds [13]. It may, as a consequence, be used more broadly in the rehabilitation of patients who, as a result of an ongoing neurodegenerative illness, have lost their ability to communicate verbally.

\section{CONCLUSIONS}

The loss of the ability to communicate with others has a serious impact upon the patient's quality of life, and often results in withdrawal and an inability to lead an independent life. The introduction of the Augmentative and Alternative Communication (AAC) system proves to be of great help, not only in regaining the ability to communicate, but also in the restoration of social bonds. In consequence, previously mute patients start to show signs of social cooperation. 


\section{REFERENCES}

1. Pąchalska M, Kaczmarek BLJ, Kropotov J.D. Neuropsychologia kliniczna. Od teorii do praktyki. Warszawa: PWN. 2014.

2. Kertesz A, Munoz DG, Primary progressive aphasia. Clin Neurosci. 1997; 4(2): 95-102.

3. Kertesz A. Frontotemporal Dementia (FTD). Acta Neuropsychol. 2011; 9(2):103-114.

4. Luzzatti C, Poeck K. An early description of slowly progressive aphasia. Arch Neurol. 1991; 48: 228-229.

5. Mesulam M-M. Slowly progressive aphasia without generalised dementia. Ann Neurol. 1982; 11: 592-598.

6. Mesulam Mesulam MM. Primary progressive aphasia. Ann Neurol. 2001; 49: 425-432.

7. Gorno-Tempini ML, Hillis AE, Weintraub S, Kertesz A, Mendez M, Cappa SF, Ogar JM, Rohrer JD, Black S, Boeve BF, Manes F, Dronkers NF, Vandenberghe R, Rascovsky K, Patterson K, Miller BL, Knopman DS, Hodges JR, Mesulam MM, Grossman M. Classification of primary progressive aphasia and its variants. Neurology. 2011 Mar 15; 76(11): 1006-1014.

8. Pick A. Über die Beziehungen der senilen Hirnatrophie zur Aphasie. Prager medicinische Wochenschrift 1892; 17: 165-167.

9. FolsteinFolstein MF, Folstein SE, McHugh PR. Mini-mental state". A practical method for grading the cognitive state of patients for the clinician. J Psychiatr Res. 1975; 12(3): 189-98.

10. Mc Khan G, Drachman D, Folstein M, et al: Clinical diagnosis of Alzheimer's disease: report of the NINCDS-ADRDA Work Group under the suspicies of Department of Health Services Task Force on Alzheimer's disease. Neurology 1984; 34: 939.

11. Hachinski VC, Lassen NA, Marshall J. Multi-infarct dementia. A cause of mental deterioration in the elderly. Lancet 1974; 2 (7874): 207-10.

12. Kertesz A. Western Aphasia Battery. New York: Grune and Stratton. 1982.

13. Pąchalska M. Metody diagnozy chorego z afazją. W: T. Gałkowski, G. Jastrzębowska (red.), Logopedia: pytania i odpowiedzi (s. 611-699). T. 2. Opole: Wydawnictwo Uniwersytetu Opolskiego. 2003.

14. Pąchalska M, MacQueen BD, Brown JW. Microgenetic theory: Brain and mind in time. In: R.W. Rieber (ed.), Encyclopedia of the history of psychological theories (p. 675-708). T. 26. Frankfurt: Springer. 2012.
15. Łuria AR. Podstawy neuropsychologii. Warszawa: PZWL. 1976.

16. Lebrun Y. Mutism. Studies in disorders of communication. London: Whurr Publishers Ltd. 1990

17. Rohrer JD, Warren JD, Rossor MN. Abnormallaughter-like vocalisations replacing speech in primary progressive aphasia. J Neurol Sci. 2009 Sep $15 ; 284(1-2)$ : $120-123$.

18. Markiewicz K. Możliwości komunikacyjne dzieci autystycznych. Lublin: Wydawnictwo UMCS; 2004.

19. Kaczmarek L. Nasze dziecko uczy się mowy. Lublin: Wydawnictwo Lubelskie; 1988.

20. Jakobson R. Fundamentals of Language, The Hague Mouton \& Co., Printers; 1956.

21. Brown JW. Microgenetic Theory and Process Thought. Exeter: Imprint Academic; 2015.

22. Brown JW, Pąchalska M. The symptom and its significance in neuropsychology. Acta Neuropsychol. 2003; 1(1): 1-11.

23. Pribram KH. The holographic hypothesis of brain functioning. In: S. Grof (wyd.), Ancient wisdom, Modern Science (p. 174-175). State University of New York Press; 1984.

24. Pąchalska M, Góral-Półrola J, Brown JW, MacQueen B. Consciousness and reality: a neuropsychological perspective. Acta Neuropsychol. 2015; 13(3): 205-227.

25. Pąchalska M, MacQueen BD, Brown JW. Microgenetic theory: Brain and mind in time. In: RW. Rieber (ed.), Encyclopedia of the history of psychological theories (p. 675-708). Vol. 26. Frankfurt: Springer; 2012a.

26. Otsuki M, Soma Y, Yoshimura N, Tsuji S. Slowly progressive limbkinetic apraxia. Eur Neurol. 1997; 37: 100-103.

27. Selnes O A, Holcomb H H, Gordon B. Progressive dysarthria: Structural and functional brain correlations. Am J Psychiatry 1996; 153: 309-310.

28. Sinnatamby R, Antoun NA, Freer CE, Miles KA, Hodges JR. Neuroradiological findings in primary progressive aphasia: CT MRI and cerebral perfusion SPECT. Neuroradiology 1996; 38: 232-238.

29. Snowden JS, Neary D, Mann DM, Goulding P J, Testa HJ. Progressive language disorder due to lobar atrophy. Ann Neurol. 1992; 31: 174-183.

30. Westbury C, Bub D. Primary progressive aphasia: A review of 112 cases.' Brain Language 1997; 60, 381-406.

31. Zakzanis KK. The neuropsychological signature of primary progressive aphasia. Brain Language 1999; 70: 70-85. 